\title{
PENGENALAN DAN PELATIHAN MENGGUNAKAN GOOGLE APPS UNTUK PEMBELAJARAN ONLINE PADA MASA PANDEMI COVID 19 DI YAYASAN JOSHUA BANGUN BANGSA
}

\author{
Ichwan Nugroho ${ }^{1}$ \\ H Jazuli Mukhtar² \\ Fifi Julfiati ${ }^{3}$ \\ Roy Mubarak ${ }^{4}$ \\ Ham Idris Tumenggung 5 \\ 1,2,3,4,5 Universitas Pamulang, Banten, Indonesia \\ dosen01962@unpam.ac.id ${ }^{1)}$ \\ dosen01829@unpam.ac.id ${ }^{2}$ \\ dosen02685@unpam.ac.id ${ }^{3}$ \\ dosen02093@unpam.ac.id $^{*}$ )
}

\author{
Kata Kunci: \\ [GoogleApps, Google \\ Drive, Gmail, Google \\ Docs, Pelatihan, PKM]
}

\begin{abstract}
Abstrak: Di era perkembangan teknologi informasi yang sangat cepat saat ini, hampir semua lapisan masyarakat memanfaatkan kemajuan teknologi informasi untuk berbagai kebutuhan hidupnya, salah satu contoh adalah di dunia pendidikan. Salah satu kemajuan teknologi informasi yang dimanfaatkan oleh dunia pendidikan adalah internet sebagai media komunikasi. Sedangkan untuk media pembelajaran lainnya yang saat ini sudah mulai banyak digunakan adalah penggunakan aplikasi secara online. Salah satu penyedia media pembelajaran online ini adalah Google LLC. Google LLC adalah sebuah perusahaan multinasional Amerika Serikat yang berkekhususan pada jasa dan produk Internet. Produk-produk tersebut meliputi teknologi pencarian, komputasi web, perangkat lunak, dan periklanan daring. Sebagian besar labanya berasal dari AdWords. Yayasan Joshua Bangun Bangsa yang bergerak di bidang pendidikan menyadari pentingnya penerapan penggunaan internet guna meningkatkan prestasi belajar siswa - siswi. Penggunaan Google Apps untuk mengotimalkan pembelajaran online di masa pandemi ini sangat penting agar sesuai dengan standar yang ditentukan pihak sekolah. Dengan memanfaatkan teknologi sekarang sangat di harapakan bisa memaksimalkan proses belajar siswasiswi secara daring.
\end{abstract}

Published by:

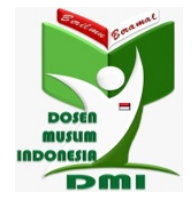

Copyright (C) 2021 The Author(s)

This article is licensed under CC BY 4.0 License (cc) $\mathrm{BY}$

https://dmi-journals.org/jai/ 


\section{Pendahuluan}

Pengetahuan tentang teknologi informasi sudah menjadi kebutuhan yang wajib dipenuhi oleh seseorang. Hal tersebut membuat hampir semua kegiatan sehari-hari seseorang melibatkan bantuan teknologi informasi, diantaranya dalam kegiatan belajarmengajar. Selain itu juga pengetahuan akan teknologi informasi merupakan modal utama seseorang untuk bersaing di era globalisasi saat ini. Google sebagai salah satu layanan teknologi informasi bagi pengguna internet menjadi populer diantara pengguna internet tersebut karena desainnya yang sederhana dan bersih serta hasil pencarianya yang relevan. Iklan dijual berdasarkan kata kunci (keyword) sehingga mereka menjadi lebih relevan bagi para pengguna, dan desain halaman tetap rapi serta loading halaman sangat cepat.

Di masa pandemi covid-19 sekarang, proses kegiatan belajar-mengajar tidaklah mudah karena membutuhkan waktu untuk beradaptasi dari yang biasanya dilakukan melalui tatap muka (offline), kini menuntut pelaksanaan secara online dengan sistem yang baru untuk bisa melakukannya. Tenaga pengajar salah satu contoh adalah dosen merupakan orang yang melakukan proses pembelajaran dan melakukan sharing ilmu di perguruan tinggi, baik itu universitas, institusi maupun akademi. Peran dosen salah satunya adalah dapat membuat perubahan di lingkungan sekitar dan bisa menyalurkan ilmu yang selama ini didapatkan agar lebih bermanfaat.

Banyak sistem dan media pembelajaran online yang bisa diperkenalkan dan dipelajari bagi stakeholder di dunia pendidikan, diantaranya bagi siswa-siswi sekolah dan para pengajar (guru). Salah satunya adalah google apps. Google apps merupakan salah satu produk dari google yang memberikan fasilitas untuk mengatur pekerjaan secara online. Edisi Standar Google Apps ini adalah gratis dan menyediakan jumlah yang sama dengan kapasitas akun Gmail Reguler. Melaui google apps ini diperkenalkan fitur-fitur antara lain Google Drive, Gmail, Google Clasroom, Google Doc, dan lain-lain

Kegiatan pengabdian kepada masyarakat merupakan bentuk aktualisasi seni budaya, sains, dan teknologi yang dilaksanakan secara langsung kepada masyarakat secara konvensional via metodologi ilmiah sebagai distribusi Tri Dharma Perguruan Tinggi yang bertimbal dengan UU Nomor 20 tahun 2003 Pasal 20:2 mengenai Sistem Pendidikan Nasional yang berisikan bahwasanya Perguruan Tinggi sudah sepatutnya memiliki kewajiban untuk melaksanakan penelitian, pendidikan dan pengabdian kepada masyarakat serta berkewajiban yang luhur dalam ikhtiar mengembangkan kapabilitas di masyarakat. Oleh karenanya dapat memberikan efek cepat pada laju pertumbuhan dan tercapainya destinasi pembangunan nasional.

Dalam upaya memperkenalkan lebih jauh tentang google apps, dilakukan melalui kegiatan PKM (Pengabdian Kepada Masyarakat) yang dapat dilakukan oleh dosen beserta mahasiswa secara bersama-sama. Kegiatan ini merupakan program yang mampu memberikan peningkatan kecerdasan, keterampilan, dan pengetahuan masyarakat seperti penataan dan perbaikan lingkungan, pelatihan keterampilan kelompok masyarakat, pengembangan kelembagaan masyarakat, dan penciptaan karya seni

Sasaran kegiatan PKM ini adalah sebagai wadah perkenalan sekaligus pelatihan mengenai pemanfaatan beberapa aplikasi Google Apps kepada siswa dan siswi di bawah naungan Yayasan Josua Bangun Bangsa. Diharapkan dengan adanya proses pelatihan ini, Yayasan Josua Bangun Bangsa dapat lebih memanfaatkan beberapa aplikasi yang ada 
dalam paket Google Apps sebagai salah satu media pembelajaran secara online. Kegiatan PKM ini mengusung tema "PENGENALAN DAN PELATIHAN UNTUK PEMBELAJARAN ONLINE PADA MASA PANDEMI DI YAYASAN JOSUA BANGUN BANGSA”.

\section{Metode Pelaksanaan}

Metode yang dilakukan pada kegiatan Pengabdian Kepada Masyarakat yang diselenggarakan secara online ini adalah metode presentasi berupa pengenalan dan pelatihan pelatihan tentang fitur-fitur yang ada pada Google Apps, agar siswa-siwi lebih paham tentang apa saja fitur-fitur yang ada pada Google Apps untuk meningkatkan pembelajaran online selama pandemi ini. Target sasaran peserta kita merupakan siswasiwi tingkat SMP dan SMK dari Yayasan Josua Bangun Bangsa yang telah ikut berpartisipasi, baik mereka yang sudah memahami materi tentang google apps ataupun mereka yang belum memahaminya. Pada kegiatan ini kita mencoba sharing dengan sesama siswa-siwi di yayasan tersebut dan berdiskusi serta memecahkan masalah bersama tentang apa yang mereka alami selama pembelajaran online saat ini. Selain pelatihan yang dilakukan, kegiatan juga dilengkapi sengan sesi tanya jawab dan juga quiz yang bertujuan agar peserta dapat berperan aktif secara langsung dan juga dapat diketahui sejauh mana pesertta dapat memahami dan mengerti tentang penggunaan Google Apps sebagai media pembelajaran secara online. Adapun waktu dan tempat pelaksanaan :

Hari dan Tanggal : Jum'at, 02 April 2021

Waktu Pelaksanaan : Pk. 13.30 - 16.30 WIB

Tempat Pelaksanaan : Online mempergunakan Google Meet

\section{Hasil dan Pembahasan}

Fokus Pengabdian Kepada Masyarakat (PKM) ini yaitu pada kelompok sasaran program pengabdian masyarakat yang meliputi siswa dan siswi SMP dan SMA Josua Bangun Bangsa sejumlah kurang lebih 30 orang. Adapun kegiatannya adalah berupa pengenalan dan pelatihan serta praktik secara langsung pemanfaatan beberapa fitur yang terdapat pada Google Apps. Beberapa fitur Google Apps yang diperkenalkan adalah: Google Drive, Gmail, Google Docs, Google Document (Document, Spreadsheet, Slide, Formulir), Google Classroom dan Google Meet.

Pelaksanaan Pengabdian Kepada Masyarakat mengenai pengenalan dan pelatihan menggunakan Google Apps untuk pembelajaran online pada masa pendemi covid 19 di Yayasan Josua Bangun Bangsa Kreo Tangerang yang dilaksanakan secara online dengan tahapan pelaksanaan (susunan acara). Adapun susunan acara pelaksanaan adalah sebagai berikut:

Tabel 1. Susunan Acara Kegiatan

\begin{tabular}{ccll}
\hline Waktu & $\begin{array}{c}\text { Durasi } \\
\text { (Menit) }\end{array}$ & \multicolumn{1}{c}{ Acara } & Penanggung Jawab \\
\hline 13:30 - 14:00 & 30 & Registrasi Peserta & Fifi Julfiati \\
14:00 -14.10 & 10 & Perkenalan Panitia Penyelenggara & Fifi Julfiati \\
$14.10-14.15$ & 5 & Sambutan Ketua Pelaksana PKM & $\begin{array}{l}\text { Ichwan Nugroho } \\
\text { 14.15 }-14.20\end{array}$ \\
\hline
\end{tabular}


Vol. 1. No. 2, Agustus 2021

\begin{tabular}{|c|c|c|c|}
\hline Waktu & $\begin{array}{c}\text { Durasi } \\
\text { (Menit) }\end{array}$ & Acara & Penanggung Jawab \\
\hline $14.20-14.30$ & 10 & Workshop Materi & Fifi Julfiati \\
\hline $14.30-15.30$ & 60 & Pelatihan Google Apps & Roy Mubarak \\
\hline $15.30-16.00$ & 30 & Sesi Tanya Jawab & Roy Mubarak \\
\hline $16.00-16.10$ & 10 & Quiz dan Pengumuman Pemenang & Fifi Julfiati \\
\hline $16.10-16.20$ & 5 & $\begin{array}{l}\text { Sambutan Kordinator Yayasan } \\
\text { Joshua Bangun Bangsa }\end{array}$ & Josep pangaribuan \\
\hline $16.20-16.25$ & 5 & $\begin{array}{l}\text { Doa bersama sesuai kepercayaan } \\
\text { masing-masing }\end{array}$ & H. Jazuli Mukhtar \\
\hline $16.25-16.30$ & 5 & Penutup \& Ramah Tamah & $\begin{array}{l}\text { Semua Panitia dan } \\
\text { Peserta }\end{array}$ \\
\hline
\end{tabular}

Pengenalan dan Pelatihan menggunakan Google Apps di Yayasan Josua Bangun Bangsa yang menjadi tema pada kegiatan PKM ini mempunya maksud dan tujuan yaitu: memberikan pengetahuan dan wawasan tentang Google Apps untuk kegiatan belajar online dan meningkatkan pengetahuan siswa-siswi tentang penggunaan Google Apps. Berikut ini kegiatan PKM yang didokumentasikan:

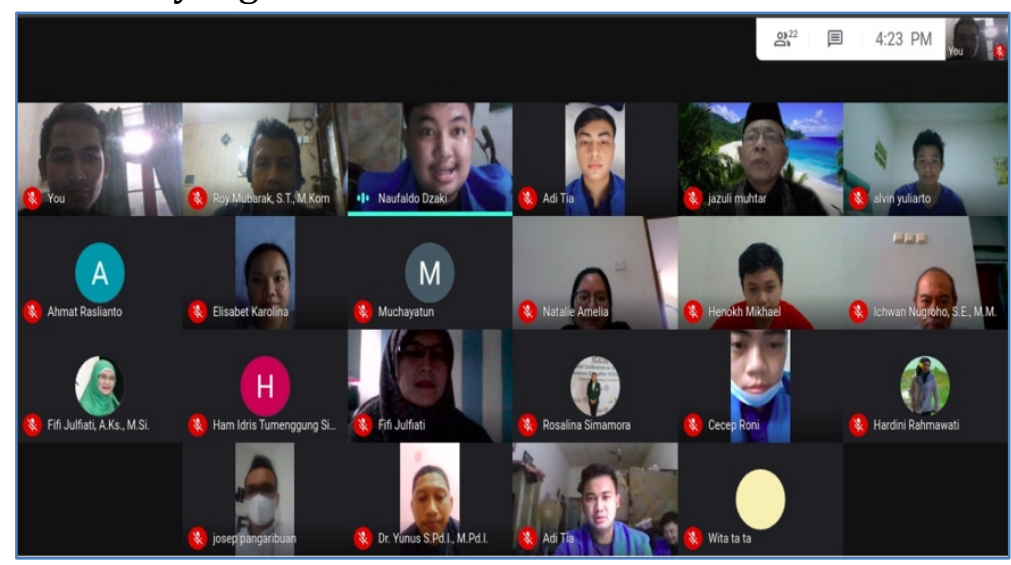

Gambar 1. Pendaftaran Peserta Pelatihan (Online)

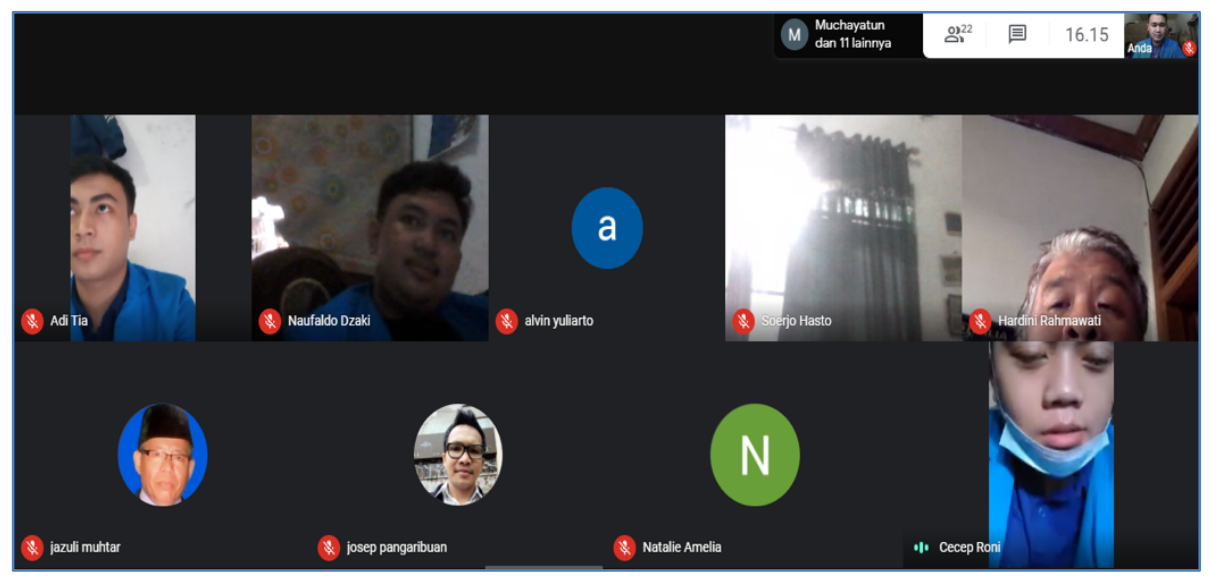

Gambar 2. Sambutan Pembawa Acara - Ibu Fifi Julfiati 


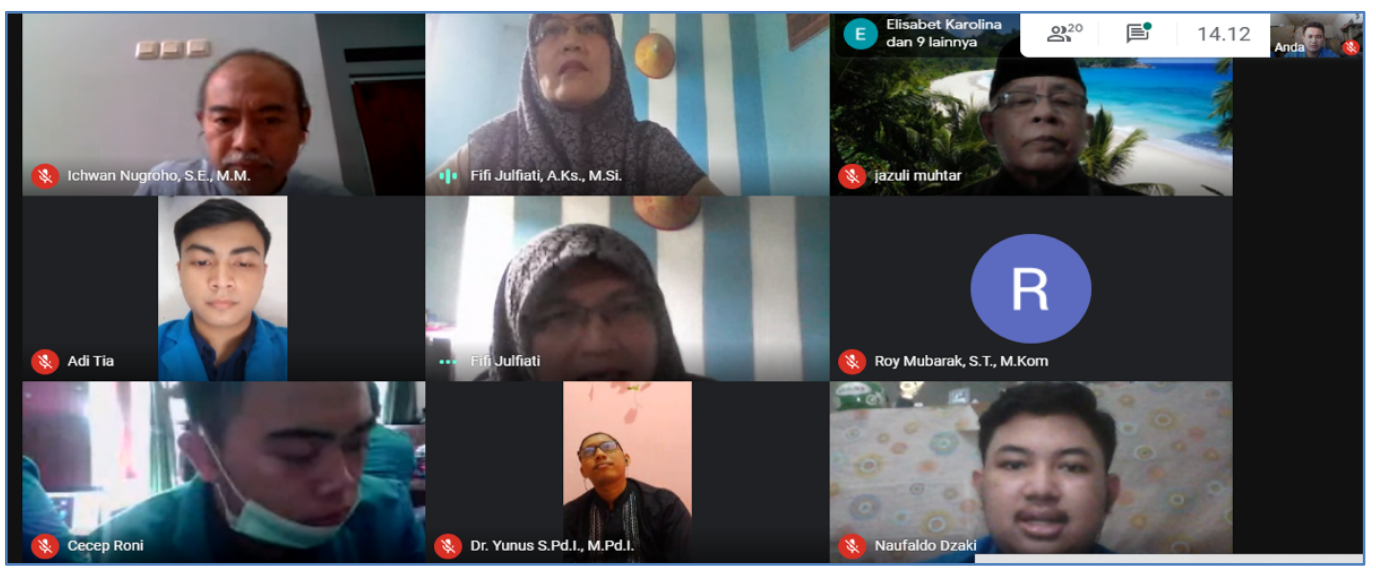

Gambar 3. Sambutan Ketua Pelaksana PKM - Bapak Ichwan Nugroho

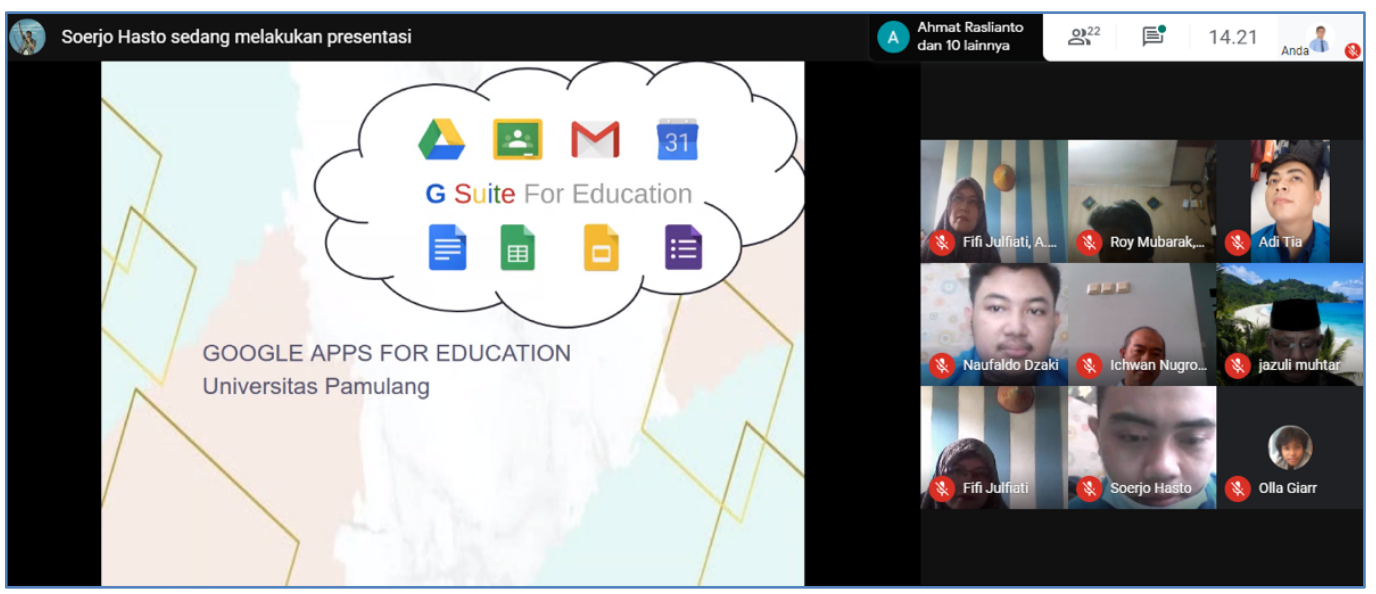

Gambar 4. Pengenalan Materi Google Apps

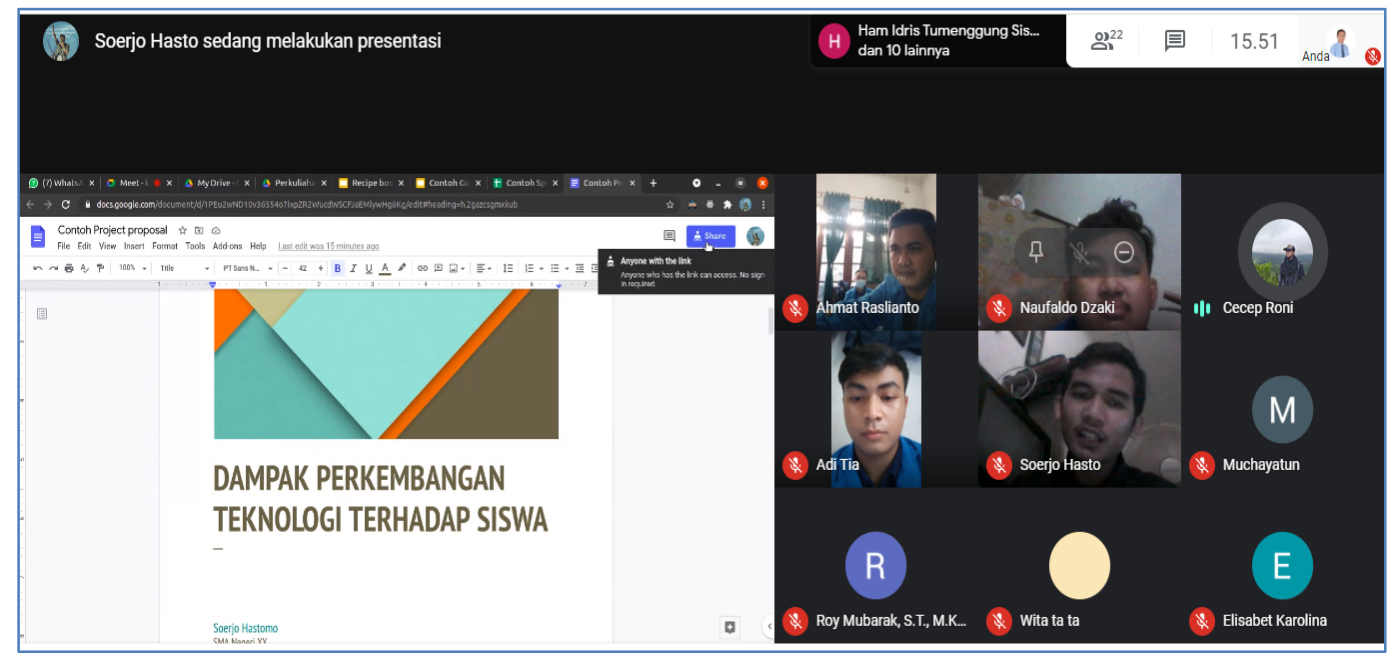

Gambar 5. Pelatihan Materi Google Apps 


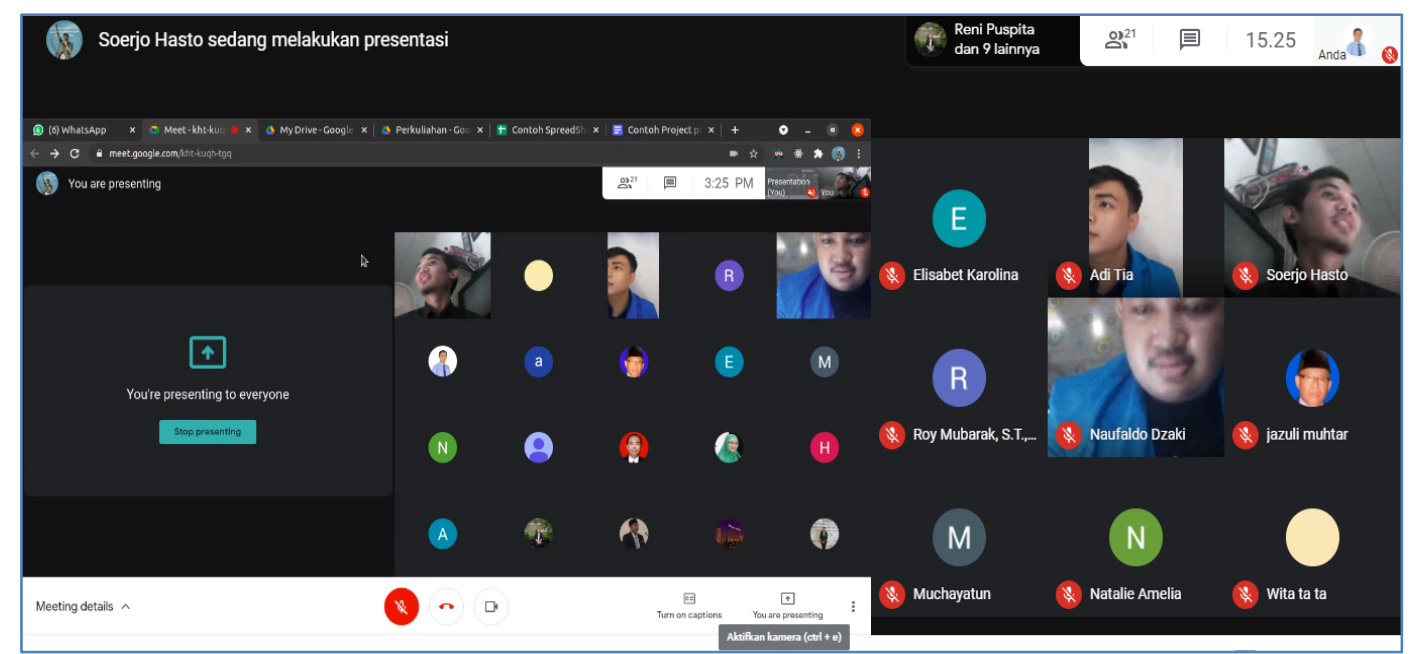

Gambar 6. Sesi Tanya Jawab

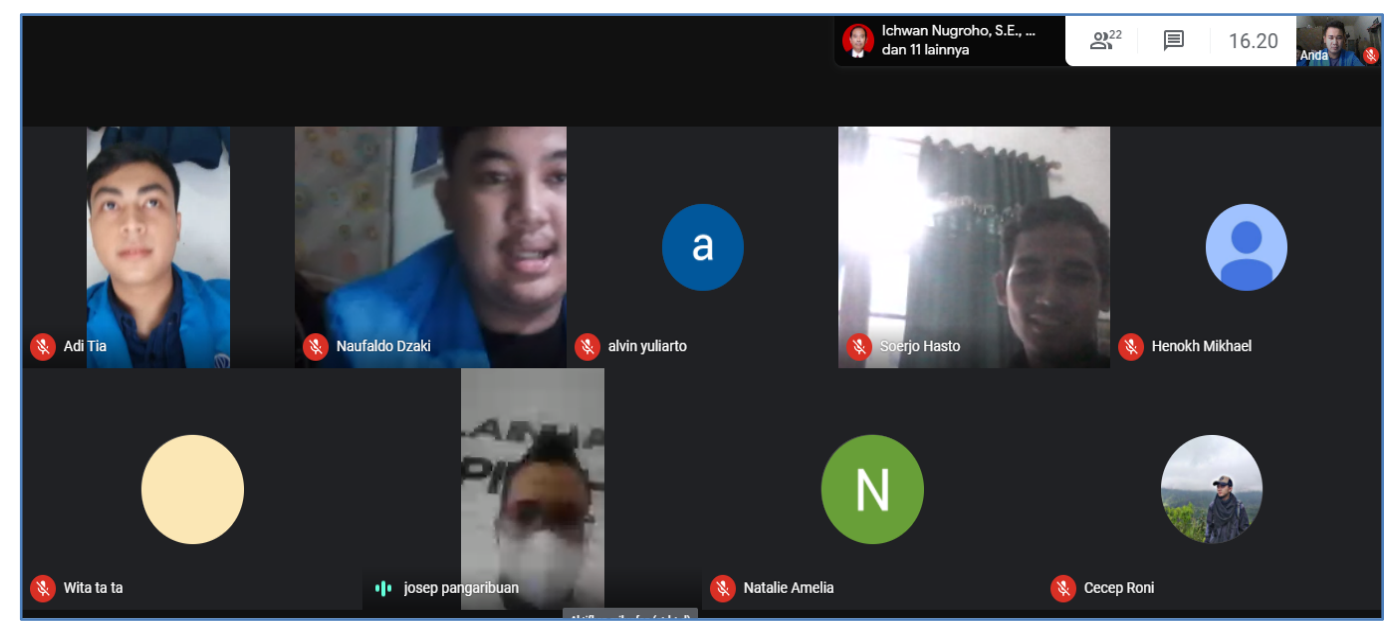

Gambar 7. Sambutan Koordinator Josua Bangun Bangsa

Kegiatan pengabdian kepada masyarakat diharapkan dapat memberikan manfaat terutama pada masyarakat yang dilakukan oleh Tim Fakultas Teknik Informatika Universitas Pamulang. Kegiatan pengabdian kepada masyarakat dapat menumbuhkan rasa keingintahuan para siswa SMP dan SMK Yayasan Josua Bangun Bangsa mengenai penggunaan Google Apps dalam pembelajaran online sehingga dapat diimplementasikan mengingat kompetensi keahlian siswa yang selaras dengan materi ini.

\section{Kesimpulan}

Dari kegiatan Pengabdian Kepada Masyarakat ini dapat diambil kesimpulan bahwa:

1. Kegiatan Pengenalan dan Pelatihan Menggunakan Google Apps untuk pembelajaran online mendapatkan apresiasi yang mendalam dari para siswa, khususnya siswa SMK Yayasan Josua Bangun Bangsa.

2. Pada pemaparan proses pemanfaatan beberapa fitur Google Apps guna mengaktualkan siswa dan siswi SMP \& SMK Yayasan Josua Bangun Bangsa untuk lebih berkualitas dalam hal penguasaan fasilitas yang ada pada Google Apps.

3. Tersampaikannya materi pelatihan yang menunjukan adanya respon positif yang diberikan pada pelatihan tersebut. 
4. Respon positif yang dirasakan oleh peserta dari pelatihan yang dilakukan panitia dikarenakan peserta mendapatkan pengetahuan baru yang sebelumnya belum mengetahui secara lebih mendalam mengenai berbagai fitur Google Apps serta terdapat kebanggaan tersendiri oleh peserta pelatihan karena mendapatkan sertifikat keikutsertaan pada kegiatan yang sudah diselenggarakan oleh panitia.

\section{Ucapan Terimakasih}

Penulis dengan segala kerendahan hati menyampaikan ucapan terima kasih kepada Bapak Achmad Udin Zailani, S.Kom.,M.Kom selaku Ketua Program Studi Teknik Informatika Program Sarjana Universitas Pamulang, Bapak Josep Pangaribuan selaku Koordinator Yayasan Josua Bangun Bangsa, serta siswa/i SMP dan SMK di bawah naungan Yayasan Josua Bangun Bangsa.

\section{Referensi}

Edy Winarno., Ali Zaki., Smit Dev Community (2013) Step by Step Aplikasi Google Apps. Gramedia.

Ifan Prihandi (2017). Tutorial Google Drive Dan Google Apps. Deepublish.

https://edu.google.com/intl/id/products/workspace-for-education/educationfundamentals/

https://riaupos.jawapos.com/teknologi/05/04/2020/228686/ini-5-fitur-google-yangbisa-menunjang-anak-belajar-di-rumah.html

https://urbandigital.id/inilah-berbagai-fitur-menarik-g-suite-untuk-pendidikan/

https://www.liputan6.com/tekno/read/4329175/google-hadirkan-berbagai-toolsbaru-untuk-dukung-pembelajaran-jarak-jauh 